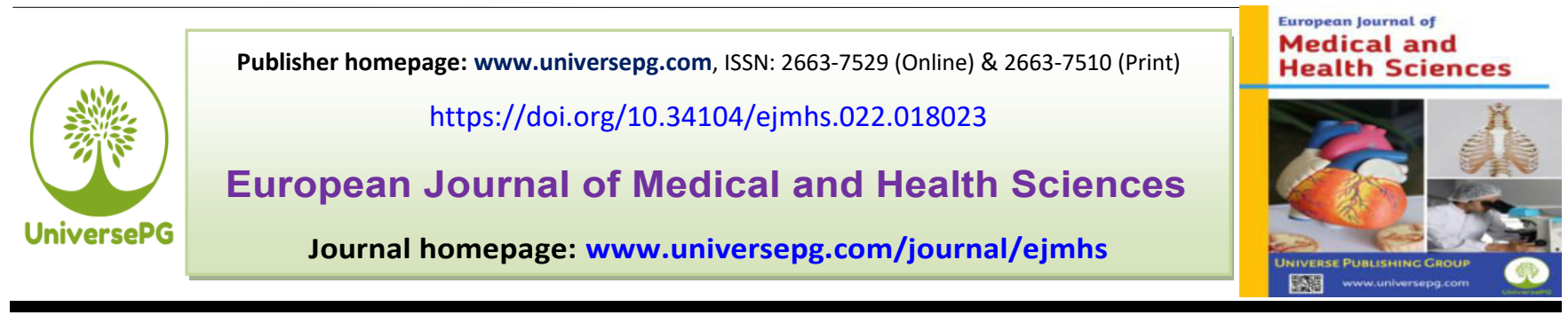

\title{
Mass Closure Comparison with Layered Closure in Midline Laparotomy Incisions
}

\author{
Ghazi Jamal Abdul Nasir ${ }^{1 *}$, Abdul Nasir Shams ${ }^{2}$, and Fahima Aram ${ }^{3}$ \\ ${ }^{1}$ Dept. of Urology and General Surgery, Nangarhar University, Teaching Hospital, Afghanistan; ${ }^{2}$ Dept. of General surgery, \\ Nangarhar University, Teaching Hospital, Afghanistan; and ${ }^{3}$ Dept. of Obstetrics and Gynaecology, Kabul Medical Uni- \\ versity, Kabul, Afghanistan. \\ *Correspondence: ghazi1973@gmail.com (Dr. Ghazi Jamal Abdul Nasir, Associate Professor, Dept. of Urology and General \\ Surgery, Nangarhar University, Teaching Hospital, Afghanistan).
}

\begin{abstract}
Incision and suturing abdominal wall is a common surgical practice and different methods of repairing and applying have aroused great interest among surgeons. This study aims to compare mass closure and layered closure in midline laparotomy incisions. This prospective comparative study was conducted in the surgical ward of Nangarhar University Hospital on 40 patients from June 2020 to June 2021. A and B were assigned to all of the patients randomly. Twenty patients received bulk closure and other twenty underwent multilayer closure. The time of surgery, wound infection, abdominal rupture, and other consequences were all compared across all patients. Patients were followed on Day 2, day 4, day 8, day 12, monthly for 3 months and after 6 months. The rate of wound infection in layered (group B) is higher as compared to mass closure (group A). In general, the wound infection rate in the multilayer closure group was 2 cases (10\%) and 1 case (5\%) in the mass closure group. In layered closure, event ratio was $10 \%$, while in mass closure it was $5 \%$. In multilayer closure, a buttonhole hernia was detected in one case (5\%) and none in mass closure. In layered closure, sinus development was seen in two cases (10\%), but not in mass closure. The method of closure by mass to close the midline laparotomy incisions is simple, easy to perform, and safer than Layered closure.
\end{abstract}

Keywords: Midline incision, Layered, Mass closure, Comparison, Laparotomy, Incisions, and complications.

\section{INTRODUCTION:}

There needs to be a clear goal behind closing the abdominal wound; in addition, it should be technically very simple and easy for the results obtained from the trainees to be like the main surgeon. The ideal approach to close the abdomen should be simple, quick and inexpensive so that we could avoid early and late complications (Kumar, 2014).

A laparotomy wound is traditionally attached to a plan that selects different classes through anatomy, which includes the technique of closing a floor such as the method of mass closing (Hodgson, 2000) where all layers of the abdominal wall except the skin and subcutaneous tissue are sewn in one layer. The skin is approached separately with cut sutures (Wissing, 1987). The practical value of any abdominal closure procedure could be judged only when it is not selected inpatients and is used by all surgeons who close abdominal wounds. Continuous mass closure technique with a non-absorbable suture material is still considered the approach of choice in most healthcare centers for midline laparotomy wound closure in both emergency and selective settings (Kendall, 1991). Abdominal ligation is a procedure that is frequently reflected in literature despite advances in surgery and 
materials. However, the personal preference of a surgeon is based on their confidence in traditional method, experience and anecdote (Israel, 1994). In abdominal surgery, the selected incisions should be wise and the methods of closing such wounds are very important elements (Khan, 2009). Inadvertent practice such as cutting in the wrong place, sewing incorrectly, or choosing poor-quality suture material can lead to serious harms such as hematoma, wound infection, suture abscess, ugly wound, incisional hernia, or worst of all, the complete disorder in the wound (Leaper, 1977). Clinical and laboratory studies performed on animals have shown when a cut is made; a dense fibrous wound forms that unite the opposite edges of the laparotomy wound into a mass. The purpose of the suture is to bring the edges of the wound closer together so that the wound becomes denser, thicker, and more mature. Sutures can potentially cut tissue when the wound closes; therefore, small bites and sutures that do not remain sufficiently longer in the wound should be used. Adequate storage of the suture length in the wound is necessary to create this lengthening and ensure that the minimum suture and tissue tension is increased (Gugnani et al., 2021).

There is a significant correlation between ratios of suture length: wound length with wound disruption; such that the lower the ratio, the higher the chance of wound rupture. In other words, a ratio of 2:1 or below is related with wound rupture and wound healing could be avoided using a ration of $4: 1$ or more and continuous non-absorbable sutures at intervals of $1 \mathrm{~cm}$ [Jenkins Law] (Carlson, 1995; Ellis, 585). Many experiments performed to determine the targeted method for closing the abdominal fascia lacked sufficient strength and the patients' treatment had conflicting results. Moreover, many surgeons were indecisive about it (Ellis, 585). Therefore, we aimed to conduct the current study to compare the two modalities of midline laparotomy wound closure (mass closure vs. layer closure) and their resultant complications and wound closure time.

\section{Literature review}

Anterior abdominal wall could be repaired by multiple techniques such as layered closure, modified SmeadJones technique, mass closure, and retention sutu (Sanders, 1977; Ceydeli, 2005) The most effective method of midline abdominal fascial closure in a systematic review was found to be mass closure with number 1 or 2 non-absorbable monofilament suture materials and a suture length to wound length ratio of 4:1 (Ceydeli, 2005). Currently used sutures have a few advantages such evenly divided tension across the suture line, being more adaptable, fewer knots and stitch sinuses, and being a single line holding the fascia together (Bucknall, 1982; Domball, 2005). Moreover, the findings of a study by Santosh et al. on 60 consecutive patients undergoing midline laparotomy incisions for intra-abdominal pathology revealed that wound closure complications were more in the layered method compared to that of the mass closure method. In fact, hematoma was $0 \%$ in both groups, seroma $0 \%$ in mass closure group and $3.33 \%$ in the layered closure group, burst abdomen $3.33 \%$ in both groups, and mean closure time of 16.2 minutes in mass closure and 21.2 minutes in layered closure group was reported (Deshmukh, 2018). In addition, a similar comparative study by Sreeharsha et al. demonstrated wound infection $8 \%$ in the layered closure group versus $6 \%$ in the mass closure group. Moreover, seroma $10 \%$ in layered closure versus $6 \%$ in mass closure, and mean closure time 23 minutes in layered closure versus 14 minutes in mass closure. However, incisional hernia was reported less $(0 \%)$ in layered closure compared to mass closure (2\%) (Sreeharsha, 2013). A study done by Ganesh S Bhavikatti and Raghavendra Gupta GHV that included 30 emergency and elective cases, infection rate was $13.33 \%$ in mass closure group but $36.66 \%$ was in layered closure group; brust abdomen was noted $0.033 \%$ in mass closure group and $0.23 \%$ in layered closure group (Bhavikatti, 2019). Results of the study performed by Akash Bande et al. showed that mean laparotomy wound closure time was $18.2 \pm 3.2$ minutes for mass closure group and $26.4 \pm 4$ minutes for layered closure group. In addition, wound dehiscence was $1.5 \%$ in mass closure group and $3.03 \%$ in layered closure group; surgical site infection was $4.6 \%$ in mass closure group and $12.12 \%$ in layered closure group (Allauddin et al., 2021; Bande, 2018)

\section{METHODOLOGY:}

This single blinded comparative trial was conducted at the surgical ward of Nangarhar University Teaching hospital over 40 individuals assigned 20 each as A and 
$\mathrm{B}$ in the intervention and control arms. Both male and female patients undergoing laparotomy were selected for the study after obtaining their written consent. 20

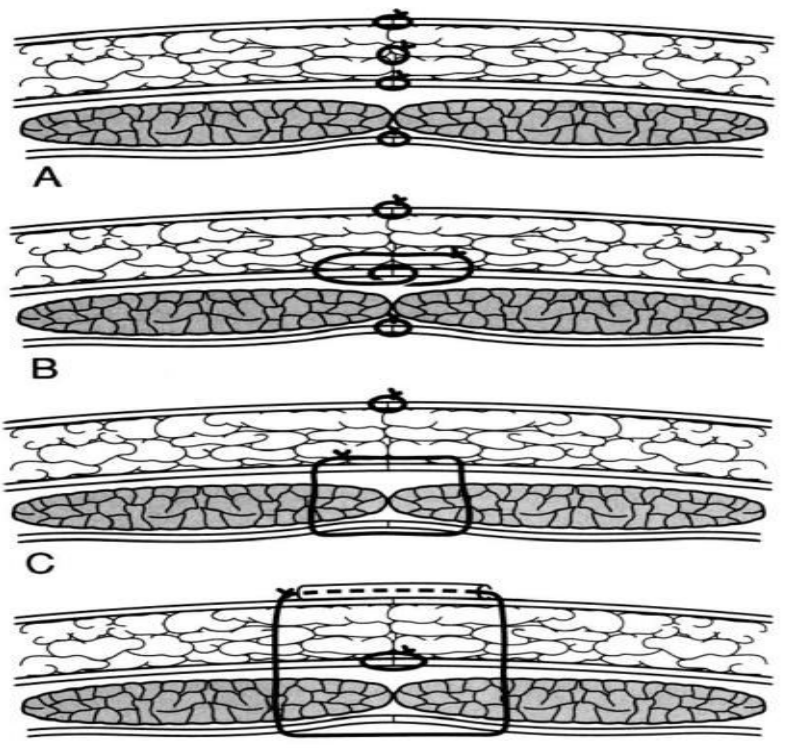

participants assigned as group A underwent mass closure while the other 20 assigned as group B underwent layered closure for the midline laparotomy.
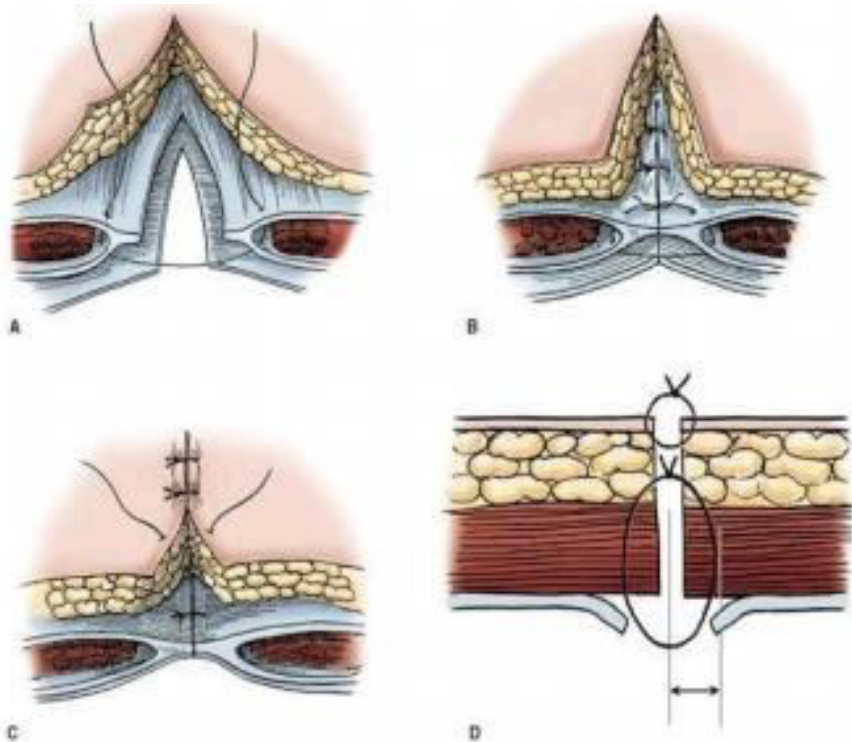

Fig.1: Mass closure (Left) and Versus Layer Closure (Right).

A thorough history was taken, and clinical examination was performed upon admission to the bed. Age, sex, education, occupation, place of residence, economic status, symptoms of related diseases were recorded after direct interview with the patient to confirm the clinical diagnosis. Necessary laboratory and radio logic investigations were ordered in each patient. Layered closure:

All of the stages were the same for the two methods of midline laparotomy closure except the fascia which was closed as a distinct layer in the layer closure; in addition, all of the layers were closed with PDS using continuously flowing sutures. All 40 patients undergoing laparotomy regardless of their gender aging 2373 years were included in the study while emergency cases, immunodeficient patients, and severely obese patients (BMI > 36) were excluded from the study. Data was stored in Microsoft excel sheet and transported to SPSS version 26 (Statistical Package for Social Science). Mean \pm standard deviation was used for continuous variables while percentage and frequency was used for categorical variables. Statistical significance of analysis was set at $\mathrm{P}<0.05$.

UniversePG I www.universepg.com

\section{RESULTS:}

In the study, 40 consecutive patients with intra-abdominal pathology underwent laparotomy with midline incision.

Table 1: Distribution according to age.

\begin{tabular}{|c|c|c|}
\hline No & Age group (years) & Total cases \& percentage \% \\
\hline 1 & $23-33$ & $9(22.5 \%)$ \\
\hline 2 & $34-43$ & $7(17.5 \%)$ \\
\hline 3 & $44-54$ & $7(17.5 \%)$ \\
\hline 4 & $55-65$ & $5(12.5 \%)$ \\
\hline 5 & $66-73$ & $12(30.0 \%)$ \\
\hline Total & 40 & $40(100 \%)$ \\
\hline
\end{tabular}

The most vulnerable age group in this study was 66 to 73 years $(30 \%)$ followed by 23 to 33 years $(22.5 \%)$.

Table 2: Incidence according to gender

\begin{tabular}{|c|c|c|c|}
\hline No & Sex & Total cases & Male: female ratio \\
\hline 1 & Male & $25(62.5 \%)$ & \multirow{2}{*}{$1.6: 1$} \\
\hline 2 & Female & $15(37.5 \%)$ & \\
\hline Total & 40 & $40(100 \%)$ & \\
\hline
\end{tabular}

Out of 40 patients, 25 were males and 15 were females with an F: M ratio of 1.6:1. Intra-abdominal pathologies that were managed through midline laparotomy incisions are listed in Table 3 where cholecystectomy was the most prevalent cause of midline laparotomy in the study participants (9.33\%). 
Table 3: Intra-abdominal issues managed through the midline laparotomy incisions.

\begin{tabular}{|c|c|c|}
\hline No & Intra-abdominal pathology & Percentage \\
\hline 1 & Cholecystectomy & $9.33 \%$ \\
\hline 2 & Gastric outlet obstruction & $2 \%$ \\
\hline 3 & Liver Hydatid cyst & $1.33 \%$ \\
\hline 4 & Pancreas pseudocyst & $0.66 \%$ \\
\hline 5 & Splenomegaly & $2 \%$ \\
\hline 6 & Lower GI cancer & $8.2 \%$ \\
\hline
\end{tabular}

Midline abdominal incision was divided into three locations as upper, middle and lower midline incision whose percentages in the participants is shown in Table 4.

Table 4: Distribution of patients according to an abdominal incision.

\begin{tabular}{|c|c|c|}
\hline No & Abdominal incision & Total cases \\
\hline 1 & Upper midline & $22(55 \%)$ \\
\hline 2 & Mid midline & $5(12.5 \%)$ \\
\hline 3 & Lower midline & $13(32.5 \%)$ \\
\hline 4 & Total & $40(100 \%)$ \\
\hline
\end{tabular}

Repair time in both mass closure and layered closure with suggested $\mathrm{p}$ value is shown in Table 5.

Table 5: Repair time.

\begin{tabular}{|c|c|c|c|}
\hline No & Type of closure & Time(mint) & p-value \\
\hline 1 & Mass closure & 15,25 & \multirow{2}{*}{$<0.006$} \\
\hline 2 & Layered closure & 20.45 & \multirow{2}{*}{. } \\
\hline
\end{tabular}

Post operative complications following midline laparotomy closure are listed in Table 6 in both methods.

Table 6: Post operative complications

\begin{tabular}{|c|c|c|c|}
\hline No & $\begin{array}{c}\text { Postoperative } \\
\text { complication }\end{array}$ & Mass closure & $\begin{array}{c}\text { Layer } \\
\text { closure }\end{array}$ \\
\hline 1 & Hematoma & $0(0 \%)$ & $0(0 \%)$ \\
\hline 2 & Seroma & $0(0 \%)$ & $2(10 \%)$ \\
\hline 3 & Wound infection & $1(5 \%)$ & $2(10 \%)$ \\
\hline 4 & Eventration & $1(5 \%)$ & $2(10 \%)$ \\
\hline 5 & Incisional hernia & $0(0 \%)$ & $1(5 \%)$ \\
\hline 6 & Sinus formation & $0(0 \%)$ & $2(10 \%)$ \\
\hline
\end{tabular}

\section{DISCUSSION:}

This is the first ever-published paper on the comparison of the two methods of midline laparotomy wound closure (mass closure vs layered closure) in Nangarhar, Afghanistan. If we compare wound infection rates in groups A (mass closure) and B (layered UniversePG I www.universepg.com closure), wound infection in the abdominal wall was $1(5 \%)$ in group A (mass closure) and $2(10 \%)$ in group B (layered closure) in our study. While in a study performed by Sreeharsha et al. wound infection was found to be $8 \%$ in the two-layered closure group and $6 \%$ in the mass closure group (Sreeharsha, 2013). In addition, in a study by Chhabra et al. wound infection was $37.5 \%$ in the layered group and $20 \%$ in the mass closure group. The studies show that wound infection is greater in the layered closure group than in the mass closure group, possibly due to excessive tissue traumatization and entrapment of tissue blood supply during the layered closure technique (Chhabra, 2020).

In current study there were a few wound closure complications. In fact, Abdominal burst was 1 case (5\%) in group A and 2 cases (10\%) in group B, Incisional hernia 0 case in group A and 2 cases (10\%) in group B, Buttonhole hernia was $0 \%$ in group $A$ and $5 \%$ in group $\mathrm{B}$, and sinus development $0 \%$ in group $\mathrm{A}$ but $5 \%$ in group B. The multilayer closure group had a $10 \%$ burst abdomen rate, whereas the mass closure group had a $5 \%$ burst abdomen rate, which is consistent with the findings of other researches. In comparison to Chhabra et al. study, the incidence of abdominal rupture was $10 \%$ in the layered group and 5\% in the mass closure group, incisional hernia was equal in both groups, and the results were similar to ours. In present study, the rate of suture sinus formation for mass closure group was $0 \%$ but $10 \%$ for layered closure. Compared with a study conducted by Santoshkumar N et al. suture sinus formation was $0 \%$ in mass closure group and $3.33 \%$ in layered closure group whose results are similar to our study in which rate of suture sinus formation was increased in layered closure group then mass closure group (Deshmukh, 2018). Time for wound closing in mass group A was 15.25 minutes and for group B (layered closure) is 20.45 minutes in the current study while in study of Singh et al. 20 minutes for mass closure and 35minutes for layered closure groups (Singh, 2012). In the current investigation, mass closure was found to be more successful than layered closure. In the current study, the rate of split abdomen was $5 \%$ in the mass closing group and $10 \%$ in the multilayer closure group compared to $2 \%$ and $4 \%$ abdomen split rate respectively in a study by Sreeharsha $e t$ al. (2013). 


\section{CONCLUSION:}

Mass closure technique for midline laparotomy wound closure compared with layered closure is simple, stronger, bearing fewer complications and less time consuming.

\section{ACKNOWLEDGEMENT:}

We would like to cordially thank Mr. Gul Agha Sadat and Miss. Silly Fazli and everyone who helped us in data collection, statistical analysis of the data and composition of the word document.

\section{CONFLICTS OF INTEREST:}

The authors declare that they have no potential conflicts of interest.

\section{REFERENCES:}

1) Allauddin, Rehman G, Zarkoon AK, Nasira B, and Khan IU. (2021). COVID-19 pandemic lockdown resulting in an unusual rectal foreign body in a young male. Eur. J. Med. Health Sci., 3(6), 132-135. https://doi.org/10.34104/ejmhs.021.01320135

2) Bande A, Saxena D, Nichkaode $P B$, Akhtar $M$. (2018). A comparative study of single layer closure versus conventional layered closure of laparotomy wounds. Int Surg J, 5, 1459-63. http://dx.doi.org/10.18203/2349-2902.isj20181130

3) Bhavikatti GS, Gupta GHVR. (2019). Comparitive Study of Mass Closure and Layered Closure Techniques in Midline and Paramedian Laparotomies. Acad. J Surg. 2(1), 42-46. http://dx.doi.org/10.21276/ajs.2019.2.1.12

4) Bucknall TE, Cox PJ, Ellis H. (1982). Burst abdomen and incisional hernia: a prospective study of 1129 major laparotomies. $\mathrm{Br} \mathrm{Med} J$, 284, 9313. https://doi.org/10.1136/bmj.284.6320.931

5) Carlson M.A., Ludwig K.A., and Condon R. E. (1995). "Ventral Hernia and Other Complications of 1000 Midline Incisions", Southern Medical Journal, 88(4), 42.

https://doi.org/10.1097/00007611-199504000-000 $\underline{13}$

6) Ceydeli A, Rucinski J, Wise L. (2005). Finding the best abdominal closure: an evidence-based review of the literature. Current Surg, 62(2), 220-5. https://doi.org/10.1016/j.cursur.2004.08.014
7) Chhabra P, Maheswari M, Kumar D. (2020). A comparison between mass closure and layered closure in laparotomy wounds. International $J$. of Medical and Health Research, 6(2), 8-11.

8) Deshmukh SN, Maske AN. (2018). Mass closure versus layered closure of midline laparotomy incisions: a prospective comparative study. Int Surg J, 5, 584-7.

9) Domball FT, Hill GL, Horrocks JC. (2005). A controlled clinical trial of three methods of closure of laparotomy wounds. Br J Surg, 62, 823-9. http://dx.doi.org/10.18203/2349-2902.isj20180357

10) Ellis H, Heddle R. (1979). Closure of abdominal wound. J R Socp; 585. https://doi.org/10.1177/014107687907200106

11) Gugnani HC, Sharma A, and Sood N. (2022). A review of Blastomycosis in Indian subcontinent. Eur. J. Med. Health Sci., 4(1), 01-07. https://doi.org/10.34104/ejmhs.022.01007

12) Hodgson NC, Malthaner RA, Cyst be T. (2000). The search for an ideal method of abdominal fascial closure: a meta-analysis. Ann Surg. p; 585. https://doi.org/10.1097/00000658-200003000-000 $\underline{18}$

13) Israel son LA, Jonson T. (1994). Closure of the midline laparotomy incisions with polydioxanone and nylon: the importance of suture technique. Br J Surg, p 9. https://doi.org/10.1002/bjs.1800811114

14) Kendall WH, Brennan G, Guillou J. (1991). Suture length ratio and the integrity of midline and lateral paramedian incisions. Br J Surg, p 9. https://doi.org/10.1002/bjs.1800780623

15) Khan NA, Shehzad K. (2009). Comparison between delayed absorbable polydioxanone and non-absorbable (prolene) suture material in abdominal wound closure. PAFMJ; 59(1), 9. https://www.pafmj.org/index.php/PAFMJ/article/vi ew/163

16) Kumar RJ et al., (2014). Comparative Study of Continuous versus Interrupted $\mathrm{X}$ Type Abdominal Fascial Closure in Reference to Burst Abdomen. Int J Sci Stud, 2(7), p; 404. https://creativecommons.org/licenses/by-nc/2.0/

17) Leaper DJ, Pollock AV, Evans M. (1977). Abdominal wound closure: a trial of nylon, poly-gly- 
colic acid and steel sutures. Br J Surg, 64, p. 9. https://doi.org/10.1002/bjs.1800640822

18) Sanders RJ, DiClemente D, Ireland K. (1977). Principles of abdominal wound closure: Animal studies. Arch Surg; 112, 1184.

https://doi.org/10.1001/archsurg.1977.0137010003 $\underline{8007}$

19) Singh G, Ahluwalia R. (2012). A comparison between mass closure and layered closure of midline abdominal incisions. Med J DY Patil Univ, 5, 23-6.

http://dx.doi.org/10.4103/0975-2870.97505
20) Sreeharsha MV. (2013). A comparative study of single layer closure and conventional layered closure of laparotomy wounds. $J$. of Evoluation of Medical and Dental Sci., 2(40), 7695- 709. http://dx.doi.org/10.18203/2349-2902.isj20180357

21) Wissing J, Van Vroonhoven TJ, Schattenkerk ME. (1987). Fascia Closure after midline laparotomy: results of a randomizedtrial. Br J Surg, 74, p 9. https://doi.org/10.1002/bjs.1800740831

Citation: Nasir GJA, Shams AN, and Aram F. (2022). Mass closure comparison with layered closure in midline laparotomy incisions. Eur. J. Med. Health Sci., 4(1), 18-23. https://doi.org/10.34104/ejmhs.022.018023 @) $\underset{\mathrm{Er}}{\mathbf{9}}$ 